\title{
AGRO\&STA
}

Journal Agroista. Vol. 5 ,No.2 November 2021

Journal home page: https://jurnal.instiperjogja.ac.id/index.php/AGl

ISSN : $2597-3835$ e-ISSN : $2684-7019$

\section{APLIKASI SISTEM INFORMASI GEOGRAFIS TERHADAP MANAJEMEN TRANSPORTASI DARI TPH KE PKS}

\section{GEOGRAPHIC INFORMATION SYSTEM APPLICATION OF TRANSPORTATION MANAGEMENT FROM TPH TO MILL}

\author{
Ibnu Azhar Putra, Betti Yuniasih, Hangger Gahara Mawandha \\ Department of Agrotechnology, Faculty of Agriculture, Stiper Agricultural Institute, \\ Yogyakarta, Indonesia \\ Email korespondensi: ibnuazhar@gmail.com
}

\begin{abstract}
This study aims to create a transportation management database, create a participatory map of the harvest path from the TPH to Mill and create a transportation management model in palm oil plantations. The study was conducted at PT. Langkat Nusantara Kepong (LNK) Tanjung Beringin Estate, Hinai District, Langkat Regency, North Sumatra. This research was conducted in May - June 2019. This research was conducted by direct measurement in the field and navigation analysis. Direct measurements in the field are done by calculating the distance from TPH to Mill, calculating the average speed of trucks when carrying FFB to Mill, calculating truck time from TPH to Mill. To measure the distance done using GPS Garmin then data from GPS is entered and analyzed with the ArcGIS program. Navigation analysis is carried out using Network Analysis in ArcGIS, where the work of Network Analysis will find the most effective and efficient way.Roads in Tanjung Beringin Gardens are distinguished by their functions as HW (Highway), MR (Main Road), CR (Collection Road) and BR (Boundrest Road). Map of the FFB transportation path from TPH to Mill via the CR line which then passes the $\mathrm{MR}$, and passes the HW that corresponds to the truck lane. The results of research conducted by direct measurement in the field of FFB to Mill are already effective and efficient compared to navigation analysis.
\end{abstract}

Keywords: Navigation Analysis, GIS, TPH, harvest transportation, palm oil 


\section{PENDAHULUAN}

Faktor transportasi menjadi faktor terpenting karena apabila Tandan Buah Segar (TBS) terlambat ke Pabrik Kelapa Sawit (PKS) akan mempengaruhi proses pengolahan, kapasitas olah dan mutu produksi akhir. Pengangkutan TBS harus dilakukan secepat mungkin agar TBS yang di panen pada hari tersebut dapat diolah langsung sehingga asam lemak bebas tidak meningkat (Hartono,2012).

Perencanaan pengangkutan TBS harusla direncanakan, dengan tujuan untuk mengatur tersedianya TBS yang akan diangkut sehingga jangka waktu antara panen dan pengolahan dapat sesuai dan seluruh TBS yang sudah di panen dapat sampai di PKS pada hari yang bersamaan. Transportasi yang lancar menyebabkan program perawatan tanaman (khususnya pemupukan) sesuai dengan rencana sehingga unit kendaraan kebun dapat dialokasikan seluruhnya terhadap kegiatan transportasi TBS pada bulan produksi puncak (Pahan,2008). Dalam merencanakan pengangkutan TBS perlu diperhatikan beberapa faktor yaitu produksi kebun (semua afdeling), hasil TBS tiap afdeling, waktu tersedianya TBS di TPH. Sistem jaringan jalan di perkebunan juga merupakan salah satu faktor penting untuk kelancaran pengangkutan TBS ke pabrik. Banyak pekerjaan di suatu areal atau blok tidak dapat dilaksanakan dengan lancar karena prasarana jalan atau jembatan tidak memadai sehingga kegiatan operasional jadi terlambat. Dalam hal ini akan dibahas masalah pengangkutan buah kelapa sawit dengan membuat peta jalan pengangkutan sehingga kegiatan operasional akan tercapai maksimal. Pemanfaatan information, computer, and technology (ICT) berbasis sistem informasi geografis (SIG) dalam manajemen transpotasi TBS di kebun kelapa sawit akan membuat pekerjaan lebih efektif dan efesien.

Sistem Informasi Geografis (SIG) atau lebih dimengerti dengan istilah Geographic Information System (GIS) yang dapat di artikan sebagai suatu alat/media untuk memasukkan, menyimpan, mengambil, memanipulasi, menganalisa, dan menampilkan data-data beratribut Geografis (data geospasial) yang dapat digunakan untuk mendukung proses pengambilan keputusan dalam perencanaan dan manajemen sumber daya alam, lingkungan, transportasi, masalah perkotaan dan administratif (Burrough, 1986).

Hubungan SIG dengan Transportasi di kebun kelapa sawit yaitu dengan teknologi tersebut kita dapat mempunyai data jumlah TPH beserta jarak dari TPH tersebut menuju PKS, sehingga tingkat terjadinya buh terlambat sampai ke PKS akan semakin sedikit. SIG dapat mempermudah pemberian petunjuk jalan truk untuk sampai ke TPH dengan cepat.

Rumusan masalah penelitian ini adalah sistem manajemen pengangkutan yang ada di kebun belum memanfaatkan perkembangan teknologi, tidak ada estimasi waktu pengangkutan TBS ke PKS, tidak ada database jalur pengangkutan TBS yang efisien. Tujuan penelitian ini adalah membuat database manajemen transportasi panen, membuat peta partisipatif jalur panen dari TPH ke PKS, membuat model analisis navigasi pengangkutan di perkebunan kelapa sawit. 


\section{METODOLOGI}

Penelitian dilaksanakan di PT. Langkat Nusantara Kepong,Kebun Tanjung Beringin, Kecamatan Hinai, Kabupaten Langkat, Provinsi Sumatera Utara. Penelitian dilaksanakan pada bulan Mei sampai dengan Juni. Metode yang digunakan pada penelitian ini adalah dengan menggunakan metode survei ke lapangan, dengan menghitung jarak dari TPH ke PKS,kemudian menghitung kecepatan rata-rata truk saat membawa TBS ke PKS, menghitung waktu truk dari TPH ke PKS. Untuk mengukur jarak menggunakan GPS garmin kemudian data dari GPS dimasukkan dan di kelola ke dalam program ArcGIS. Dari pengelolaan data dari GPS didapatkan peta jalan dari TPH ke PKS pada Kebun Tanjung Beringin PT.Langkat Nusantara Kepong (LNK). Dari data yang terkumpul dilakukan analisa data. Analisa data dilakukan menurut pengukuran di lapangan dan analisa navigasi.

\section{HASIL DAN PEMBAHASAN}

PT. Langkat Nusantara Kepong (LNK), PTPN II menjalin Kerja Sama Operasi (KSO) dengan PT Langkat Nusantara Kepong PTPN II (persero) merupakan BUMN perkebunan terletak di Medan, Sumatera Utara yang melakukan KSO pengelolaan perkebunan kelapa sawit dan karet. Total luas kebun Tanjung Beringin 3.936 Ha dan dibagi menjadi 4 divisi. Lokasi Kebun Tanjung Beringin menggunakan ukuran jarak tanam 8,84 × 8,84 meter dengan jumlah populasi perhektar sebanyak 145 pokok. Tabel 1 menunjukkan informasi luas rata-rata blok dan jumlah blok.

Tabel 1. Luas Blok dan Jumlah Blok Divisi di Kebun Tanjung Beringin

\begin{tabular}{ccc}
\hline Divisi & Jumlah Blok & Luas Blok Rata- Rata (Hektar) \\
\hline 1 & 13 & 74,88 \\
2 & 12 & 82,31 \\
3 & 14 & 58,35 \\
4 & 11 & 79,79 \\
\hline
\end{tabular}

Berdasarkan fungsinya jalan di PT.LNK dibedakan menjadi jalan Highway (HW), Main Road (MR), Collection Road (CR), dan Boundrest Road (BR), seperti pada tabel 2 sebagai berikut.

Tabel 2 . Tipe jalan Kebun Tanjung Beringin PT. LNK. 
Journal Agroista. Vol. 5, No.2, November 2021 ISSN : 2597 - 3835 \& e-ISSN : 2684 - 7019

\begin{tabular}{lcccl}
$\begin{array}{l}\text { Tipe } \\
\text { Jalan }\end{array}$ & $\begin{array}{c}\text { Lebar Jalan } \\
\text { (meter) }\end{array}$ & $\begin{array}{c}\text { Tipe } \\
\text { Pengerasan }\end{array}$ & $\begin{array}{c}\text { Total Panjang } \\
\text { (meter) }\end{array}$ & Fungsi \\
\hline HW & $8-10$ & Batu & 10.258 & Jalan dari divisi menuju PKS \\
MR & $7-8$ & Batu & 32.190 & $\begin{array}{l}\text { Jalan dari divisi menuju PKS yang } \\
\text { berasal dari CR }\end{array}$ \\
CR & $4-6$ & Batu & 216.950 & Jalan untuk mengeluarkan TBS dari blok \\
BR & & & & \\
& 4 & Batu & 42.068 & Jalur kontroling \\
\hline
\end{tabular}

Tabel 3 Panjang Jalan dan rata- rata panjang MR dan Cr tiap blok di masing - masing Divisi Kebun Tanjung Beringing PT.LNK.

\begin{tabular}{ccccc}
\hline Divisi & \multicolumn{3}{c}{ MR } & \multicolumn{2}{c}{ CR } \\
\cline { 2 - 5 } & $\begin{array}{c}\text { Panjang Total } \\
(\text { meter })\end{array}$ & $\begin{array}{c}\text { Rata-rata Blok } \\
\text { (meter) }\end{array}$ & $\begin{array}{c}\text { Panjang Total } \\
(\text { meter })\end{array}$ & $\begin{array}{c}\text { Rata-rata Blok } \\
\text { (meter) }\end{array}$ \\
\hline 1 & 8700 & 863.90 & 836.84 & 835.43 \\
2 & 5254 & 872.33 & 510 & 614.00 \\
3 & 8507 & 604.27 & 377.41 & 391.27 \\
4 & 5848 & 881.91 & 548.58 & 623.13 \\
\hline
\end{tabular}

Pada Tabel diperoleh informasi panjang jalan MR dan CR di masing - masing divisi. Untuk menghitung panjang CR tiap blok dilakukan dengan mengambil sampel CR dan dihitung rata- rata, sedangkan untuk perhitungan MR dilakukan dengan digitasi mengikuti jalan MR. Pengangkutan TBS kelapa sawit dari TPH ke PKS melalui jalan CR dan MR, TBS diangkut dari TPH menggunakan Truk. TBS yang sudah dipanen kemudian diangkut menuju pabrik kelapa sawit (PKS) yang terletak di Kebun Gohor Lama Kecamatan Wampu, Kabupaten Langkat, Sumatera Utara untuk dilakukan proses pengolahan.

Tabel 4. Titik Kordinat dan jarak terhadap Divisi dan PKS

\begin{tabular}{|c|c|c|c|c|c|}
\hline \multicolumn{2}{|c|}{ Bangunan } & \multicolumn{2}{|c|}{ Kordinat } & \multirow{2}{*}{$\begin{array}{c}\text { Jarak ke PKS } \\
(\mathrm{Km})\end{array}$} & \multirow{2}{*}{$\begin{array}{c}\text { Panjang jalan } \\
(\mathrm{Km})\end{array}$} \\
\hline & & $x$ & $y$ & & \\
\hline \multirow{4}{*}{$\begin{array}{l}\text { Kantor } \\
\text { divisi }\end{array}$} & 1 & 98.40336897 & 3.838174967 & 8.6 & 9.6 \\
\hline & 2 & 98.41062603 & 3.809872968 & 5.8 & 7.17 \\
\hline & 3 & 98.39702404 & 3.77285203 & 1.4 & 1.78 \\
\hline & 4 & 98.401143 & 3.795163 & 3.9 & 4.4 \\
\hline PKS & & 98.392222 & 3.761111 & 0 & 0 \\
\hline
\end{tabular}


Pengukuran jarak dilakukan dengan digitasi pada ArcGIS yang kemudian dihitung menggunakan Calculate Geometry dan dihitung jarak lurusnya. Pada tabel 4 di atas merupakan hasil dari perhitungan jarak dari masing - masing kantor divisi menuju PKS. Jarak jalan lebih panjang karena mengikuti rute jalan yang ada baik jalan MR dan CR.

Pemetaan jalur pengangkutan TBS dari 4 divisi kebun Tanjung Beringin dapat di informasi kan pada gambar 1. Untuk lokasi TPH berada pada antar baris di pinggir CR dengan ukuran $3 \mathrm{~m} \times 2 \mathrm{~m}$. Setiap 1 hektar terdapat $3 \mathrm{TPH}$. Hasil pengukuran jarak dan waktu tempuh dari TPH ke PKS yaitu terdapat pada tabel 5 sebagai berikut.

Tabel 5. Hasil pengangkutan TBS ke PKS di lapangan

\begin{tabular}{rlrrrr}
\hline Divisi & \multicolumn{1}{c}{ Blok } & \multicolumn{2}{c}{ Jarak } & Waktu & \multicolumn{2}{c}{$\begin{array}{c}\text { Kecepatan rata } \\
\text { rata } \\
(\mathrm{Km})\end{array}$} & \multicolumn{2}{c}{$\begin{array}{c}\text { Kapasitas truk(Ton) } \\
(\text { Km/Jam })\end{array}$} \\
\hline 1 H & 11.27 & 0.73 & 15.38 & 7.2 \\
2 A & 5.76 & 0.4 & 14.37 & 7.1 \\
3 2008A & 5.13 & 0.36 & 14.25 & 7.3 \\
4 P & 7.23 & 0.57 & 12.68 & 8 \\
\hline
\end{tabular}




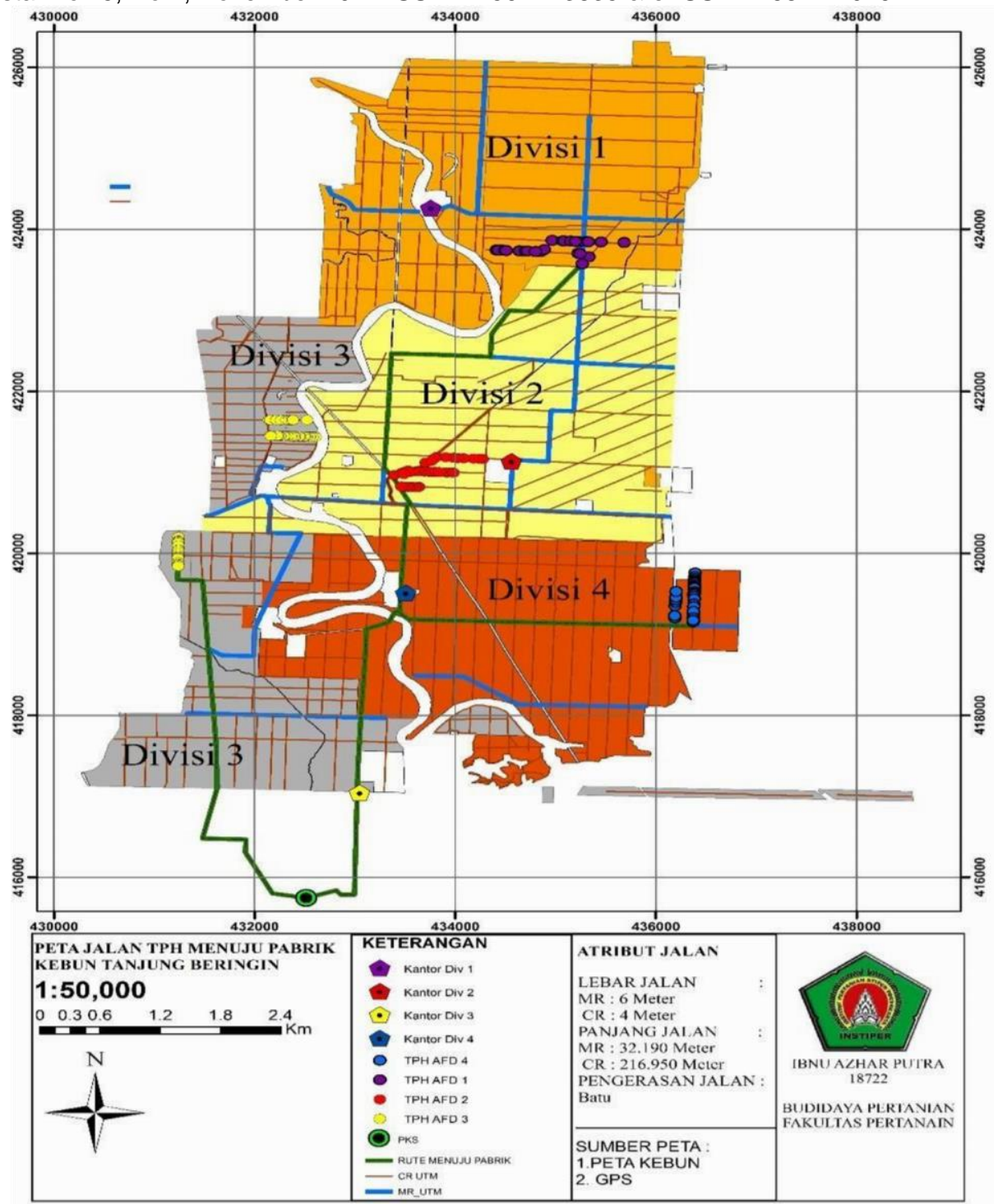

Gambar 1. Peta jalan truk pengangkutan TBS

Analisa navigasi dilakukan menggunakan Network analisis di ArcGIS. Dimana cara kerja Network analisis ini akan mencari jalan yang efektif dan efesien . Jika kita dari dari TPH menuju PKS maka kita hanya mengklik TPH dan mengklik di PKS maka jalur yang efektif dan efesien akan otomatis keluar, dari jalur tersebut maka akan otomatis keluar jarak tempuh dari TPH tersebut menuju PKS. Hasil Network analisis beserta jarak tempuhnya terdapat pada gambar 2 dan Gambar 3 sebagai berikut. 


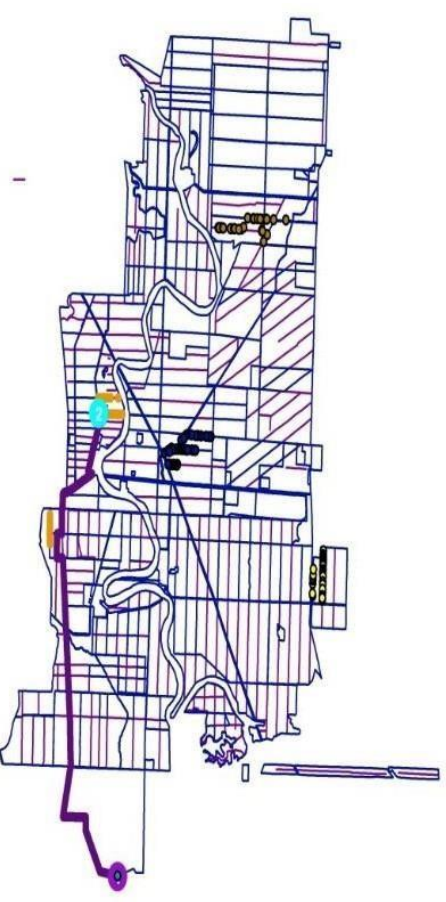

Gambar 2. Hasil Network Analisis jalan di Kebun Tanjung Beringin

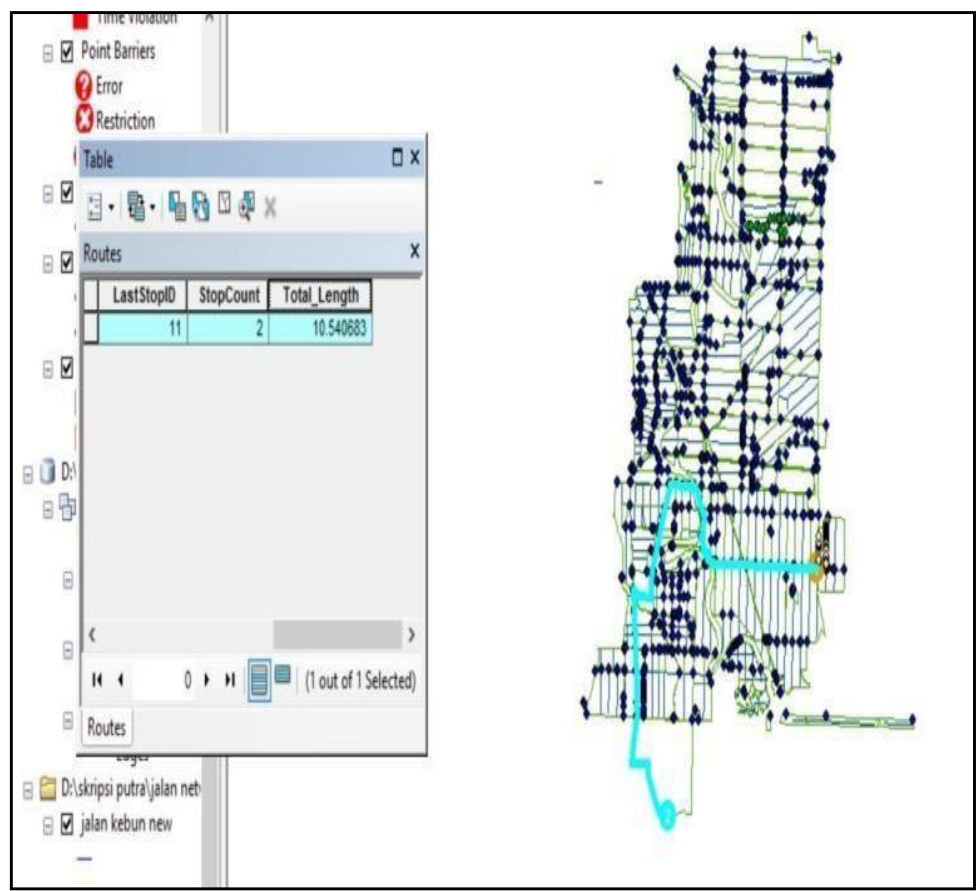

Gambar. 3. Contoh pengaplikasian Network Analisis

Tabel 6. Perbandingan hasil pengukuran jarak di lapangan dengan modelling menggunakan Network Analisis.

Perbandingan data Pengukuran langsung dan Analisis Navigasi

DIVISI TPH Jarak ke PKS (Km)

Pengukuran langsung Analisi s Navigasi

58 | Aplikasi system informasi geografis... ---- Ibnu Azhar Putra,dkk. 
Dari tabel 4.6 didapatkan bahwa pengukuran langsung di lapangan lebih efektif dan efisien daripada analisis navigasi. Pengukuran langsung di lapangan dilakukan dengan cara mengikuti truk pengangkutan hingga menuju ke PKS. Analisis navigasi dilakukan dengan menggunakan tool atau eksistensi dari aplikasi ArcGIS yang kemudian akan menunjukkan jalan dan beserta ukurannya. Penggunaan metode modeling ini dapat mencegah buah restan yang sebagian disebabkan lambatnya truk pengangkutan pada saat di jalan. Hasil pengukuran langsung di lapangan dapat dijadikan data yang cukup akurat untuk data pengangkutan serta peta pengangkutan TBS di Kebun Tanjung Beringin.

Analisis navigasi tidak menunjukkan hasil yang efektif dan efesien dikarenakan terdapat data digitasi yang tidak terkoneksi antara satu dengan lainnya. Untuk melakukan analisis navigasi, maka data digitasi harus terkoneksi sehingga data analisis navigasi dapat menunjukkan hasil yang efektif dan efesien. Data yamg digunakan untuk digitasi pada analisis navigasi berbentuk polyline. Selain dari data polyline, analisis Navigasi tidak dapat menunjukkan jalan yang akan keluar secara otomatis.

\section{KESIMPULAN}

1. Jalan di Kebun Tanjung Beringin dibedakan berdasarkan fungsinya menjadi HW (Highway), MR(Main Road), CR(Collection Road) dan BR (Boundrest Road).

2. Peta jalur pengangkutan TBS dari TPH ke PKS melalui jalur CR yang kemudian melewati $\mathrm{MR}$, dan melewati HW yang sesuai dengan jalur truk.

3. Analisis navigasi menunjukkan hasil yang kurang efisien dibanding jalur pengangkutan TBS yang sudah ada saat ini di kebun.

4. Tipe pengerasan jalan menggunakan batu dengan lebar jalan HW 8-10-meter, MR 7-8 meter, CR 4-6 meter, dan BR 4 meter

\section{DAFTAR PUSTAKA}

Anderson, M. D. and R. R. Souleyrette. 1996. Geographic Information System-Based Transportation Forecast Model for Small Urbanized Areas. Transportation Research Record Journal of the Transportation Research Board

Burrough, P.A.1986. Principles of geographical information systems for land resources assessment. Oxford University Press

Hartono H. 2012. Sukses Besar Budidaya Kelapa Sawit. Citra Media Publishing. Yogyakarta. 
Journal Agroista. Vol. 5, No.2, November 2021 ISSN : 2597 - 3835 \& e-ISSN : 2684 - 7019

Krisdiarto, A. W. and L. Sutiarso. 2016. Study on Oil Palm Fresh Fruit Bunch Bruise in Harvesting and Transportation to Quality. Makara J. Technol. 20 (2). 67-72

Lubis, R.E. dan A. Widanarko. 2011. Buku Pintar Kelapa Sawit. Agromedia Pustaka. Jakarta Pahan,I.2008. Panduan Lengkap Kelapa Sawit.Jakarta:Penebar Swadaya.

Pardamean, M. 2017. Kupas Tuntas Agribisnis Kelapa Sawit. Penebar swadaya. Jakarta 